\title{
Incidental finding of COVID-19 infection amongst staff at a primary care facility in Ghana
}

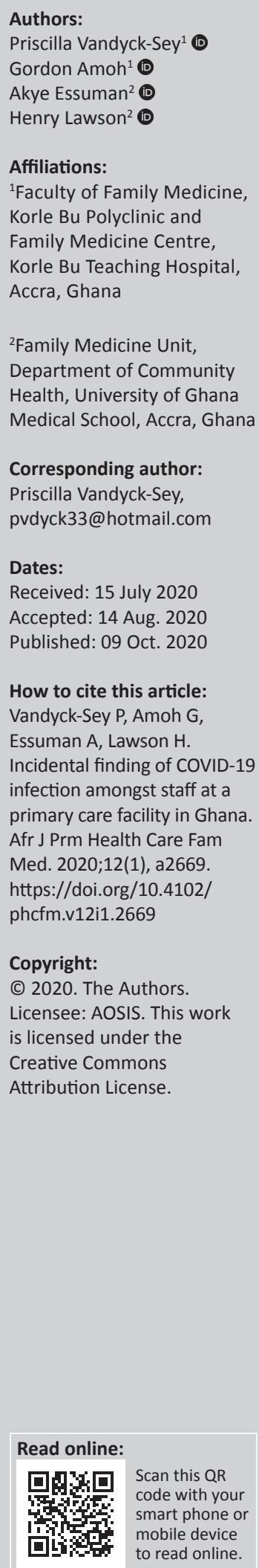

The COVID-19 pandemic has affected nearly every country worldwide and all African countries. The issue of healthcare workers (HCWs) contracting the disease is a growing concern in Ghana, because of the risk of spreading infections amongst themselves and to vulnerable patients in their care. This article illustrates how 14 staff at the Korle $\mathrm{Bu}$ Polyclinic/Family Medicine Department were incidentally found to be Covid-19 positive with most of them being asymptomatic. This observation led to a modification of the personal protective equipment (PPE) used by clinical staff when attending to patients. Furthermore, this finding suggests that a different criteria or guideline may be needed for testing of HCWs during a pandemic where a significant proportion of infected people are asymptomatic. We conclude that in the primary care setting HCWs must be ready to see all the following cases safely: routine patients, asymptomatic COVID-19 patients and suspected COVID-19 patients.

Keywords: COVID-19 infection; healthcare worker; staff; Ghana; incidental finding; modified PPE.

\section{Background}

Ghana's first two cases of COVID-19 infections were reported on 12 March 2020, the current situation stands at 37812 cases, with 34313 recoveries and 191 deaths as at 31 July 2020. ${ }^{1}$ Data from the Ghana Health Service (GHS) suggest that there is active community transmission and the first asymptomatic cases were reported on 15 April 2020. ${ }^{2}$ Infections in healthcare workers (HCWs) are a growing concern and a number of reports have been made across the country. The Ghana News Agency reported in June 2020 that about 110 HCWs had been infected ${ }^{3}$ whilst $^{2}$ The Ghana Report, published on 04 July 2020, stated that over 150 HCWs had been infected with six deaths including four doctors. ${ }^{4}$ In addition, GHS is said to have confirmed that over $2000 \mathrm{HCW}$ s have been infected with COVID-19 after the first two cases in Ghana was reported by CNN edition. ${ }^{5}$

\section{Purpose}

The Korle Bu Polyclinic/Family Medicine Department (KPFMD) is the Family Medicine training centre and provider of primary care at Korle Bu Teaching Hospital (KBTH). This article will share how some staff at the department were incidentally found to be Covid-19 positive and how the department handled the situation.

\section{Path to discovery and actions}

On 28 March 2020, a 28-year-old female patient (A.B.) with no known medical conditions, visited the KPFMD around 5:00 pm. On 03 April 2020, the KPFMD discovered that A.B. was a primary contact of a HCW in another department in $\mathrm{KBTH}$, who had tested positive for COVID-19 disease. A retrospective review of A.B.'s clinical notes revealed that she had presented at our Out-Patient Department (OPD) with symptoms of fever $\left(37.9^{\circ} \mathrm{C}\right)$, general malaise and chills. The patient A.B. neither had an international travel history nor contact with a person who had recently travelled. She had no headache, cough, sore throat, running nose or any other symptoms suggestive of Covid-19 disease and hence, was treated as a routine case. After a normal physical examination, testing negative for malaria and a normal urinalysis, she was given a clinical diagnosis of 'Fever - unspecified' and was managed on outpatient basis with oral paracetamol and vitamin $\mathrm{C}$. She visited only the OPD and laboratory at presentation and was at the KPFMD for approximately $3 \mathrm{~h}$ and $30 \mathrm{~min}$ (5:00 pm - 8:30 pm). 
At the time we made the discovery that A.B. was a primary contact to a confirmed case, her sample had already been taken for COVID-19 testing by the Public health team of $\mathrm{KBTH}$. However, her results were not yet ready, hence, possible contacts of A.B. in our department could not be screened then. Moreover, if outcome of her test was negative, no staff screening would be necessary and if positive, staff will then need to be screened. Four days later (07 April 2020), A.B.'s status changed to a confirmed case of COVID-19 disease. It had then been 10 days since A.B. presented and some staff could not remember whether they had come into direct contact with A.B or not. Subsequently, 43 clinical and non-clinical staff on duty in the afternoon and night on the day A.B. presented were screened on 09 April 2020. This was day 12 after the 'exposure'. Nasopharyngeal washings using $5 \mathrm{~mL}$ of normal saline were used to collect samples for screening. Screening was organised by the KBTH COVID-19 taskforce team under the Public Health Unit and the samples were run at the National Public Health Reference Laboratory. Results were ready after 7 days.

\section{Ethical consideration}

Permission to use secondary data was sought from hospital authorities.

\section{Results}

Because of the outcome of results of these 43 staff (see Table 1), a number of actions were taken:

1. All other staff in the KPFMD were screened for COVID-19 disease because it was apparent that there were staff who were asymptomatic carriers in some units (Tables 1 and 2).

2. On 17 April 2020, 20 days (20) after A.B.'s visit, the KPFMD was closed down for cleaning and disinfection whilst awaiting COVID-19 test results.

3. Staff who tested positive for the COVID-19 virus were admitted to designated national COVID-19 treatment centres for further management.

4. The KPFMD reopened on 29 April 2020 with staff who tested negative.
5. A second (mop-up) screening for all staff who missed the initial screening-1 was also conducted on 07 May 2020 (Table 1).

6. We reduced our work shift from three $(8 \mathrm{am}-2 \mathrm{pm}$, $2 \mathrm{pm}-8 \mathrm{pm}$ and $8 \mathrm{pm}-8 \mathrm{am})$ to two 12-h shifts ( $8 \mathrm{am}-8 \mathrm{pm}$ and $8 \mathrm{pm}-8 \mathrm{am})$ per day.

7. All clinical staff were instructed to wear goggles or face shields in addition to medical/surgical masks and reusable surgical gowns with disposable rubber aprons whilst attending to routine cases and suspected cases of COVID-19. Hazmat suits, N-95 masks with head covers, aprons and shoe covers were to be worn when reviewing detained suspected cases.

\section{Discussion}

The patient record of A.B. showed that staff who had proven evidence of contact such as the nurse who checked her vital

TABLE 2: Socio-demography and disease presentation of positive staff.

\begin{tabular}{llcc}
\hline Variable & Category & \multicolumn{2}{c}{ All $N=\mathbf{1 4}$ (\%) } \\
\cline { 2 - 4 } Sex & Male & $\boldsymbol{n}$ & $\%$ \\
\hline Age (years) & Female & 4 & 28.6 \\
& $<20$ & 10 & 71.4 \\
& $20-29$ & 1 & 7.1 \\
& $30-39$ & 3 & 21.4 \\
Nature of disease & $40-49$ & 9 & 64.3 \\
manifestation & $50-59$ & 0 & 0.00 \\
Health worker category & Asymptomatic & 1 & 7.1 \\
Clinical & Symptomatic & 1 & 92.9 \\
& & 7.1 \\
& Nurse & 4 & 28.6 \\
Non-clinical & Pharmacist & 1 & 7.1 \\
& Orderly & 3 & 21.4 \\
& Laboratory scientist & 1 & 7.1 \\
Associated comorbidities & Banker & 2 & 14.3 \\
& Security officer & 1 & 7.1 \\
& Records officer & 1 & 7.1 \\
& ICT & 1 & 7.1 \\
\hline & Hypertension & 2 & 14.3 \\
& Bronchial Asthma & 1 & 7.1 \\
& None & 11 & 78.6 \\
\hline
\end{tabular}

ICT, Information Communication Technology.

TABLE 1: Positivity rate of staff screening.

\begin{tabular}{|c|c|c|c|c|c|c|c|}
\hline Staff description & $\begin{array}{l}\text { Total screened } \\
\text { for COVID-19 }\end{array}$ & $\begin{array}{l}\text { Number } \\
\text { Negative }\end{array}$ & $\begin{array}{l}\text { Number } \\
\text { positive }\end{array}$ & $\begin{array}{l}\text { Number with inadequate } \\
\text { sample/need to repeat }\end{array}$ & $\begin{array}{l}\text { Positivity } \\
\text { rate }(\%)\end{array}$ & $\begin{array}{l}\text { Unit(s) with staff } \\
\text { testing positive }\end{array}$ & $\begin{array}{c}\text { Number } \\
\text { positive in units }\end{array}$ \\
\hline \multirow{5}{*}{$\begin{array}{l}\text { Staff on afternoon and } \\
\text { evening duty on } 28 \\
\text { March } 2020\end{array}$} & \multirow[t]{5}{*}{43} & \multirow[t]{5}{*}{27} & \multirow[t]{5}{*}{6} & \multirow[t]{5}{*}{10} & \multirow[t]{5}{*}{14} & OPD & 3 \\
\hline & & & & & & Male ward & 1 \\
\hline & & & & & & Records & 1 \\
\hline & & & & & & Bank & 1 \\
\hline & & & & & & Security & 1 \\
\hline \multirow{4}{*}{$\begin{array}{l}\text { All other Staff } \\
\text { screening-1 }\end{array}$} & \multirow[t]{4}{*}{236} & \multirow[t]{4}{*}{231} & \multirow[t]{4}{*}{5} & \multirow[t]{4}{*}{ Nil } & \multirow[t]{4}{*}{2.1} & Hospitality & 2 \\
\hline & & & & & & Pharmacy & 1 \\
\hline & & & & & & Laboratory & 1 \\
\hline & & & & & & Female ward & 1 \\
\hline \multirow{3}{*}{$\begin{array}{l}\text { All other Staff } \\
\text { screening-2 } \\
\text { (Mop-up) }\end{array}$} & \multirow[t]{3}{*}{39} & \multirow[t]{3}{*}{36} & \multirow[t]{3}{*}{3} & \multirow[t]{3}{*}{ Nil } & \multirow[t]{3}{*}{7.7} & Hospitality & 1 \\
\hline & & & & & & Bank & 1 \\
\hline & & & & & & $\mathrm{ICT}$ & 1 \\
\hline Overall total & 318 & 294 & 14 & 10 & 4.4 & 10 units & 14 \\
\hline
\end{tabular}

OPD, Out-Patient Department. 
signs, the doctor she consulted and the laboratory technician who took her blood sample all tested negative. Some staff who tested positive were not directly involved in A.B.'s care but were screened because they were on duty on the said date. The positivity rate amongst the initially 'exposed' staff, $(14 \%)$ was about 11 times higher than the national rate of $1.26 \%$ as at 15 April $2020 .^{2}$ The overall positivity rate after total staff screening was $4.4 \%$, over 3 times higher than the national rate at the time. In total, 10 female $(71 \%)$ and 4 male (29\%) staff were affected (Table 2 ) and this may be as a result of majority of frontline HCW being females. ${ }^{6}$ This contrasted with what was in the general population where $60 \%$ of all those infected were males and $40 \%$ were females. ${ }^{2}$ Interestingly, neither office staff nor doctor was affected in the department then. A total of $13(92.9 \%)$ out of 14 infected staff were asymptomatic and only 1 person had mild symptoms prior to being screened (Table 2).

Most HCWs are considered at high-risk of getting infected with COVID-19 virus. Their risk of exposure to infection is from both suspected and confirmed cases. The risk is potentially higher at the primary care setting where undifferentiated cases are largely seen. This is further compounded by the fact that appropriate PPE may not be used in attending to asymptomatic COVID-19 cases.

However, it is difficult to ascertain whether all healthcare worker infections are nosocomial in nature. At the time of staff screening, there had been no confirmed cases of COVID-19 infection amongst patients or staff in the department. There was ample evidence at the time that community transmission was ongoing as $71 \%$ of those found to be infected in the country had no travel history and 4 out of 5 new cases reported by GHS on 15 April 2020 were asymptomatic. $^{2}$

\section{Conclusion}

It became apparent from our experience that both clinical and non-clinical staff are at risk of getting infected or stand the risk of infecting other categories of staff who may not be in their respective units. A significant step we took, was to modify the prescribed use of PPE for clinical staff. Prior to the detection of COVID-19 infection amongst staff, clinical staff wore disposable gowns, goggles, disposable aprons, head covers, N95 masks or medical masks to attend to suspected cases of COVID-19 only. Upon re-opening the department after our incidental finding, these PPE are being used for both routine and suspected COVID-19 cases. However, the disposable gowns have been replaced by reusable surgical gowns. In addition, hazmat suits, N95 masks, face shields or goggles and boots are used whilst attending to detained suspected cases in the holding bay. The WHO recommends the use of the above combination of PPE for suspected cases. ${ }^{7}$ However, in the primary care setting, with majority of COVID-19 infections being asymptomatic, it may be difficult to predict who should actually be suspected for COVID-19 infection. The use of the reusable surgical gowns has been sustainable as the
KPFMD has taken advantage of an existing laundry and Central Sterile Supply Department (CSSD) process already available in KBTH. The cost of a cycle of washing and disinfection of one reusable surgical gown is about GHS 20.00 (\$3.40) and is more affordable than the disposable gown, which costs about GHS 120.00 (\$20.69) and was discarded after use.

Different guidelines and criteria may need to be developed for screening HCWs during a pandemic, which has a significant number of people as asymptomatic carriers. This will protect HCWs from spreading infections amongst themselves and to vulnerable patients in their care. Delayed turnaround time for COVID-19 test results also slows the needed action of isolation and treatment of affected staff to mitigate further spread.

We conclude that in the primary care setting, HCWs must be ready to see all the following cases safely: routine patients, asymptomatic COVID-19 patients and suspected COVID-19 patients.

\section{Acknowledgements}

Dr David Opare, Head, National Public Health Reference Laboratory; Dr Philip Amoo, Head, Public Health Unit, KBTH \& his team; Dr Ali Samba, Medical Director, KBTH; Dr Harry Akoto, Deputy Medical Director, KBTH; Dr Franklin Acheampong, Head, Research Unit, KBTH and All staff of Korle Bu Polyclinic/Family Medicine Department.

\section{Competing interests}

The authors have declared that no competing interests exist.

\section{Authors' contributions}

All authors contributed significantly to this work.

\section{Funding information}

This research received no specific grant from any funding agency in the public, commercial or not-for-profit sectors.

\section{Data availability statement}

The data are not publicly available because of restrictions, for example, they contain information that could compromise the privacy of staff and key patient.

\section{Disclaimer}

The views and opinions expressed in this article are those of the authors and do not necessarily reflect the official policy or position of any affiliated agency of the authors.

\section{References}

1. Ghanahealthservice.org. COVID-19 latest update [homepage on the Internet] Ghana; 2020 [cited 2020 Aug 4]. Available from: https://www.ghanahealthservice. org/covid19/latest.php 
2. Ghanahealthservice.org. Situation update, COVID-19 outbreak in Ghana as at 15th April 2020, updates [homepage on the Internet]. Ghana; 2020 [cited
2020 Jul 5]. Available from: https://ghanahealthservice.org/covid19/archive.php\#

3. The Ghana News Agency. MyJoyOnline.com. More than 110 health workers test positive for Covid-19 in central region - Myjoyonline.com [homepage on the Internet]. 2020 [cited $2020 \mathrm{Jul}$ 4]. Available from: https://www.myjoyonline.com/ news/regional/more-than-110-health-workers-test-positive-for-covid-19-incentral-region/

4. Alamisi D. Coronavirus: 4 doctors dead in under 4 months, 150 health workers infected - GMA Thomepage on the Internet]. The Ghana Report. 2020 [cited $2020 \mathrm{Jul} \mathrm{4}$. Available from: https://www.theghanareport.com/coronavirus-4 doctors-dead-in-under-4-months-150-health-workers-infected-gma/
5. Adamu Z. Over 2000 health care workers in Ghana have been infected with coronavirus [homepage on the Internet]. www.edition.cnn.com. 2020 [cited 2020 Aug 1]. Available from: https://edition.cnn.com/2020/07/18/africa/ghanahealthcare-workers-coronavirus/index.html

6. Farrar J. Why we need women's leadership in the COVID-19 response [homepage on the Internet]. World Economic Forum. 2020 [cited 2020 Aug 1]. Available from: https://www.weforum.org/agenda/2020/04/women-female-leadership-gendercoronavirus-covid19-response/

7. Apps.who.int. Rational use of personal protective equipment for coronavirus disease COVID-19) and considerations during severe shortages [homepage on the Internet]. 2020 [cited 2020 Aug 1]. Available from: https://apps.who.int/iris/bitstream/ handle/10665/331695/WHO-2019-nCov-IPC PPE use-2020.3-eng.pdf?ua=1 